\title{
Neoplasia Intra-epitelial Grau III da Vulva e da Região Perianal Tratada com Vulvectomia Superficial: Relato de Caso
}

\author{
High-grade Vulvar and Perianal Intraepithelial Neoplasia Treated with \\ Skinning Vulvectomy: A Case Report
}

\author{
Walquíria Quida Salles Pereira Primo, Margarida Helena Serejo Machado \\ Etelvino de Souza Trindade, Paulo Arlindo Polcheira \\ Miriam Helena Hoechl Abreu, Dúnya Bachour Basílio
}

\begin{abstract}
RESUMO
A neoplasia intra-epitelial vulvar grau III (NIV III) se manifesta de modo visivel, portanto, acessivel à biópsia e, por conseguinte, ao diagnóstico histológico. Há duas formas precursoras do câncer vulvar: a NIV associada ao papiloma vírus humano (HPV) e a NIV associada ao líquen simples crônico, hiperplasia de células escamosas e líquen escleroso, não tratados. Porém, pode existir sobreposição das duas formas. O termo papulose bowenóide, apesar de ser desencorajado, define uma das formas clínicas da NIV, que se apresenta como lesões pigmentadas, verruciformes, papulares e múltiplas. A NIV III está associada com HPV em mais de $80 \%$ dos casos e em $40 \%$ das vezes, nota-se envolvimento perianal. O seu tratamento é muito dificil e pode ocorrer recorrência em qualquer tempo e por muitos anos. Embora não exista tratamento padrão definido, os trabalhos apontam para a cirurgia, respeitando margem de segurança, como o mais adequado.
\end{abstract}

PALAVRAS-CHAVE: Neoplasia intra-epitelial vulvar (NIV). Neoplasia intra-epitelial perianal. Vulvectomia.

\section{Introdução}

A incidência da neoplasia intra-epitelial vulvar (NIV) quase duplicou nas últimas duas décadas, passando de 1,2 a 2,1/100.000 mulheresano, podendo se desenvolver em qualquer idade ${ }^{1}$.

A etiopatogenia da NIV pode ser viral e não viral. Quando acomete pacientes entre 35 e 55 anos está mais freqüentemente relacionada ao papilomavirus humano (HPV), mas em pacientes com idade superior a 55 anos, geralmente está associada a processo inflamatório crônico (líquen simples crônico e/ou líquen escleroso e/ou hiperplasia de células escamosas), podendo coexistir com o HPV ${ }^{2}$.

Unidade de Ginecologia Oncológica do Hospital de Base do Distrito Federal da Secretaria da Saúde do Distrito Federal Walquíria Quida Salles Pereira Primo

SHIS QI 21 Conjunto 4 Casa 7 - Lago Sul

71655-240 - Brasília - DF

Fone: (61) 366-4861 / 9968-7340

e-mail: walquiriaqspp@uol.com.br
A importância em se conhecer a história natural da NIV está em prevenir o câncer de vulva e de se evitarem cirurgias radicais para o seu tratamento. Quando o HPV está envolvido no início do desenvolvimento da neoplasia, esta pode evoluir para multicentricidade. Os tipos de HPV mais encontrados são os 16,31 e $33^{3}$. O tabagismo é fator de risco importante para o desenvolvimento do câncer de vulva ${ }^{4}$.

O liquen escleroso é doença crônica que surge principalmente no período peri e pós-menopausa (média de 54 anos), contudo pode aparecer em outras fases da vida. A etiologia não é conhecida. Vários fatores têm sido implicados na sua gênese, como fatores genéticos, hormonais, imunológicos e locais ${ }^{5}$. Apesar de não ser lesão pré-maligna, 3\% das portadoras podem desenvolver carcinoma de vulva. Os sintomas mais comuns são: prurido, ardência e dispareunia. Essa doença pode ser a base para o surgimento do liquen simples crônico, assim como, da candidiase, do diabete melito, da NIV, etc ${ }^{5}$.

O diagnóstico das NIVs se faz por meio da biópsia, havendo três tipos histopatológicos: 
basalóide (indiferenciado), verrucoso (condilomatoso) e bem diferenciado (simples), com comportamentos biológicos diferentes ${ }^{6}$. A NIV clássica, que corresponde aos tipos histológicos basalóide e verrucoso, tem envolvimento multifocal, multicêntrico, acomete pacientes mais jovens e em 53 a 90\% dos casos há associação com o HPV. A NIV simples, tipo histológico bem diferenciado, ocorre em mulheres na pós-menopausa e geralmente não está associada ao $\mathrm{HPV}^{6}$.

O termo papulose bowenóide, apesar de ser desencorajado, define uma das formas clinicas da NIV mais comum. Apresenta-se como lesões pigmentadas, verruciformes, papulares, múltiplas e está associada à presença do DNA do HPV. A faixa etária mais freqüente está entre 30 e 50 anos. Cerca de 60 a $80 \%$ das pacientes são tabagistas ${ }^{2,6}$.

A NIV pode regredir espontaneamente ou após remoção cirúrgica incompleta e pode persistir ou, quando não tratada, progredir para o câncer invasivo ${ }^{2}$. Segundo Pala et al. ${ }^{7}$, pode haver regressão espontânea da forma clínica papulose bowenóide em até $20 \%$ dos casos. No estudo de Basta et $a .^{8}$, a regressão da NIV I e NIV II foi de $34,7 \%$ dos casos e a progressão para câncer invasivo, de 26,4\%. Esses autores afirmaram que o tipo histológico basalóide e bem diferenciado das lesões parece progredir mais freqüentemente para o carcinoma invasivo. Para Jones e Rowan ${ }^{9}$, o tempo médio de regressão espontânea de NIV II e III foi de 9,5 meses, num estudo realizado com quatorze pacientes, entre 15 e 27 de idade, enquanto aguardavam o tratamento. Apesar de as lesões com essas características terem evolução benigna, o câncer de vulva ocorre em $2,6 \%$ dos casos $^{3}$.

A maioria das lesões (75 a 85\%) se localiza em áreas sem pêlos, em 30\% dos casos são multifocais e estão associadas com neoplasia intra-epitelial perianal em 40\% dos casos ${ }^{2}$. Outros autores afirmam que $70 \%$ das NIVs são multifocais $^{10}$. A freqüência da multicentricidade diminui com a idade ${ }^{1,4,11}$. O comportamento da NIV III é diferente da neoplasia intra-epitelial cervical grau III (NIC), e a progressão dessas lesões para câncer invasivo é de 2 a 4\% e 12 a 36\%, respectivamente $^{1,11}$. O sintoma mais freqüente é o prurido vulvar de grau variado, em cerca de 60 a $70 \%$ das pacientes ${ }^{10}$.

O objetivo deste relato é avaliar o tratamento cirúrgico da NIV III e da neoplasia intra-epitelial perianal grau III. O tratamento realizado foi vulvectomia superficial sem enxerto, que consiste na remoção da pele com as lesões, num plano relativamente avascular entre a derme e o tecido subcutâneo, com a preservação do tecido subcutâneo e do clitóris ${ }^{12}$.

\section{Relato de Caso}

Paciente MCSM, 58 anos, branca, natural do Rio de Janeiro, casada. Menarca aos nove anos. Início da vida sexual aos quinze anos, referindo ter tido dois parceiros e ser nulipara. Refere uso de anticoncepcional oral hormonal por sete anos. Menopausa aos cinqüenta anos e desde então vem usando terapia de reposição hormonal. É tabagista (sete cigarros por dia) desde vinte e oito anos de idade. Os antecedentes patológicos são: diabete melito, hipertensão arterial e obesidade, controlados. É acompanhada pelo cardiologista e endocrinologista. Nega passado de doença sexualmente transmissivel. A primeira consulta foi realizada em agosto de 2002, no serviço de Ginecologia Oncológica do Hospital de Base do Distrito Federal.

A queixa principal era prurido de longa data e ardência vulvar há cinco meses, que a impedia de dormir bem, associado à presença de "manchas escuras" na vulva. Diante desse quadro, decidiu procurar assistência médica.

$\mathrm{O}$ exame físico geral era normal. No exame ginecológico foi constatada a presença de múltiplas lesões, isoladas e confluentes, hiperqueratinizadas, pigmentadas, com bordas bem definidas, papulares, envolvendo os grandes lábios e região perianal. A maior concentração das lesões se localizava na região superior dos grandes lábios. A pele vulvar se encontrava com aspecto pálido, com poucos pêlos e foi observado o apagamento dos pequenos lábios, sugerindo líquen escleroso e/ou líquen simples crônico (Figura 1).

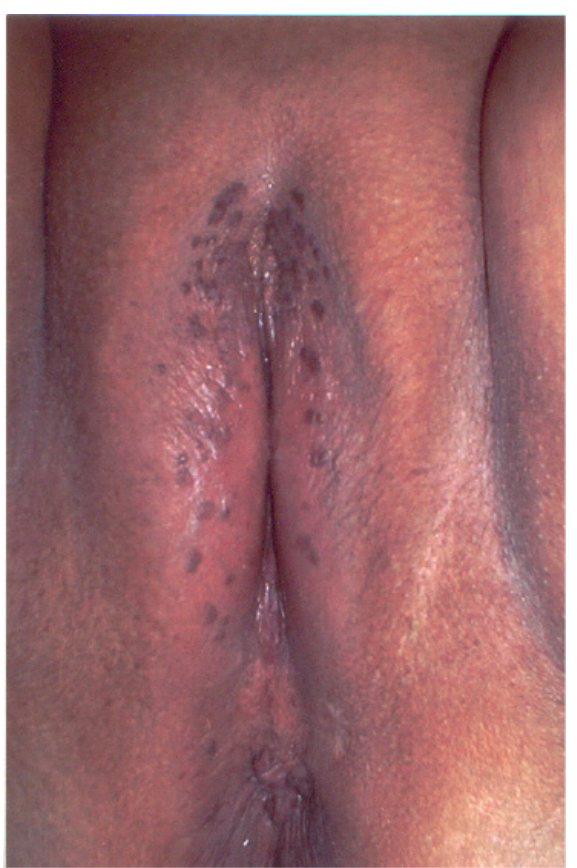

Figura 1 - Exame da vulva e da região perianal: presença de múltiplas lesões pigmentadas, hiperqueratinizadas e papulares. A pele apresenta-se pálida, com poucos pêlos e verifica-se 0 apagamento dos pequenos lábios. 
O resultado da colpocitologia foi normal. Foi realizada colposcopia de todo o trato genital inferior, sendo observado orifício externo do colo do útero circular, sem muco. A junção escamocolunar situava-se no nível do orifício externo do canal cervical. O teste do ácido acético a 5\% e o teste de Schiller foram negativos no colo do útero. Vagina sem alterações. Na vulva observaram-se lesões pigmentadas, hiperqueratinizadas, papulares isoladas e coalescentes. O teste com o ácido acético foi positivo na região superior dos grandes lábios, sendo mais intenso na região superior à esquerda. Na região perianal havia lesões com as mesmas características das lesões vulvares, mas em menor quantidade e isoladas. A anuscopia com ácido acético a $2 \%$ foi negativa. A biópsia foi realizada de acordo com a gravidade colposcópica: dois fragmentos da vulva e um da região perianal.

O material para captura híbrida foi colhido do colo, fundo de saco, vulva e ânus com os seguintes resultados: colo/fundo de saco vaginal - RLU/PCA (unidade de luz relativa/controles positivos para virus do grupo I) = 0,37 e RLU/PCB (unidade de luz relativa/controles positivos para virus do grupo II) = 0,43; vulva $-\mathrm{RLU} / \mathrm{PCA}=0,25$ e RLU $/ \mathrm{PCB}=1,24$, e ânus - RLU/PCA = 0,33 e RLU/PCB = 0,87.

$O$ resultado da biópsia foi neoplasia intraepitelial grau III da vulva e da região perianal. Com esse resultado foi programado o tratamento cirúrgico para outubro de 2002.

A cirurgia realizada foi vulvectomia superficial com preservação do clitóris. As lesões remanescentes na região perianal foram fulguradas. A cirurgia consistiu na retirada da pele na junção da derme com o tecido subcutâneo, sem enxerto (Figuras 2, 3, 4, 5).

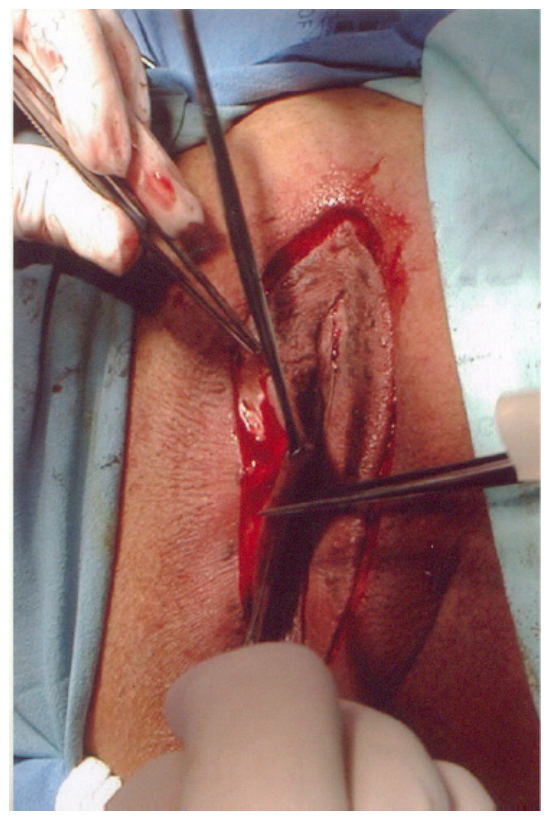

Figura 2 - Realização da incisão na margem externa dos grandes lábios.

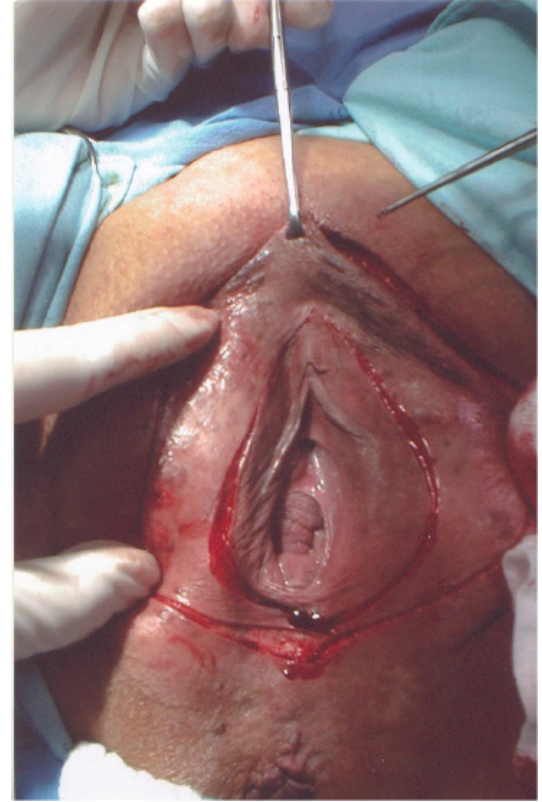

Figura 3 - Realização da incisão na margem interna dos pequenos lábios, com preservação do clitóris.

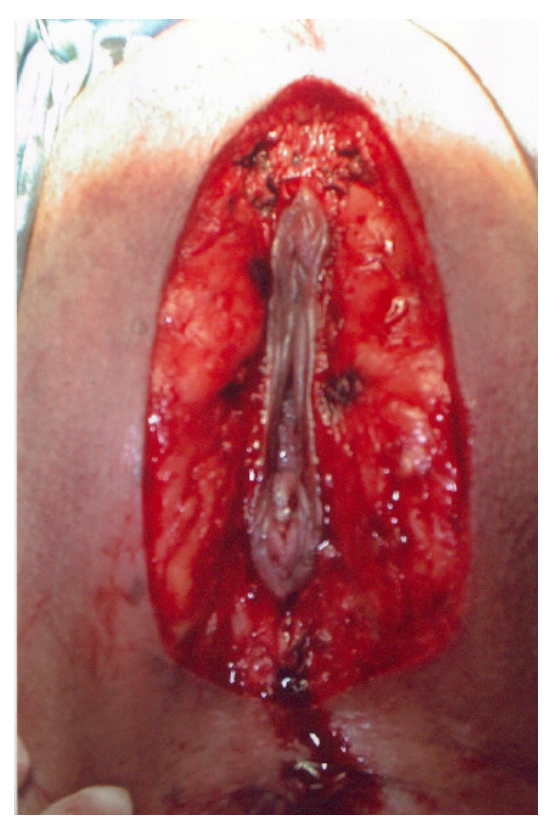

Figura 4 - Retirada da pele. Tecido subcutâneo preservado.

No pós-operatório a paciente referiu dor na região perianal, sem outras anormalidades. Recebeu alta hospitalar no terceiro dia.

O resultado do histopatológico da peça operatória foi grau III, com margens comprometidas e com aspecto basalóide; líquen simples crônico e neoplasia intra-epitelial grau III da região perianal (Figura 6). 


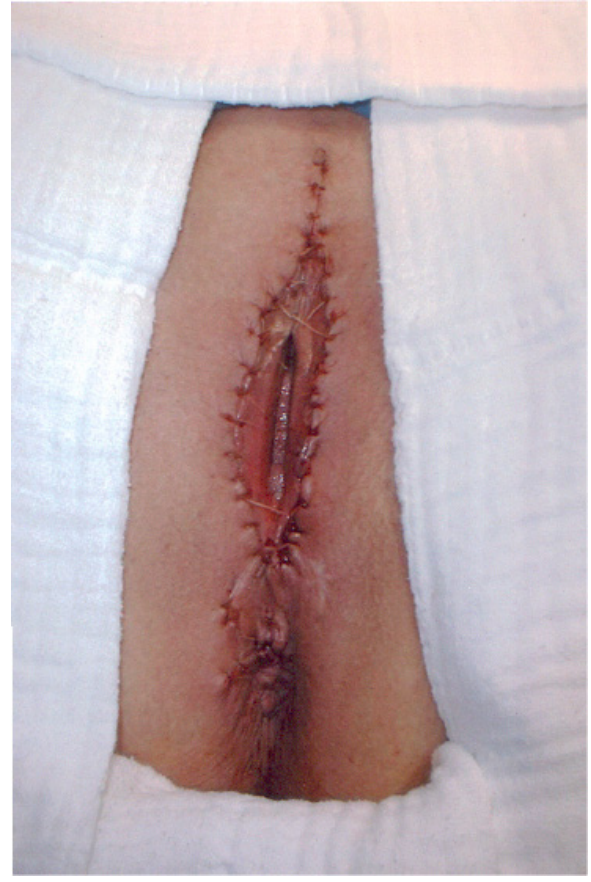

Figura 5 - Aspecto da área operada após suturas.

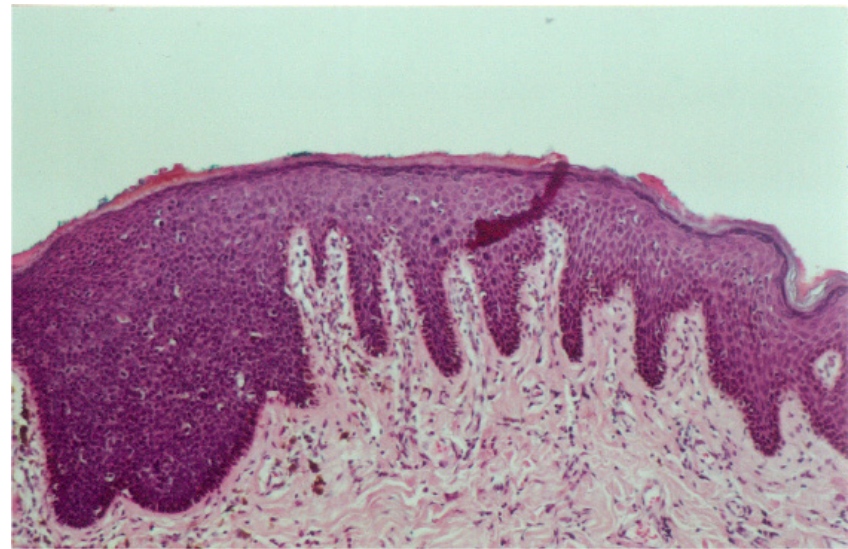

Figura 6 - Fotomicrografia: NIV III com aspecto basalóide e líquen simples crônico (HE 40X).

No quadragésimo quinto dia do pós-operatório a paciente não apresentava nenhum sintoma e referiu o desaparecimento completo do prurido genital, que a incomodava há anos, demonstrando grande satisfação pelo resultado clínico e estético da sua cirurgia. No exame ginecológico não foi constatada lesão macroscópica e a vulvoscopia estava normal (Figura 7).

O seguimento foi programado para cada três meses até completar um ano, e após com retorno de seis em seis meses. A paciente continua o acompanhamento e sem alterações ginecológicas até o momento. A última avaliação foi realizada em março de 2003.

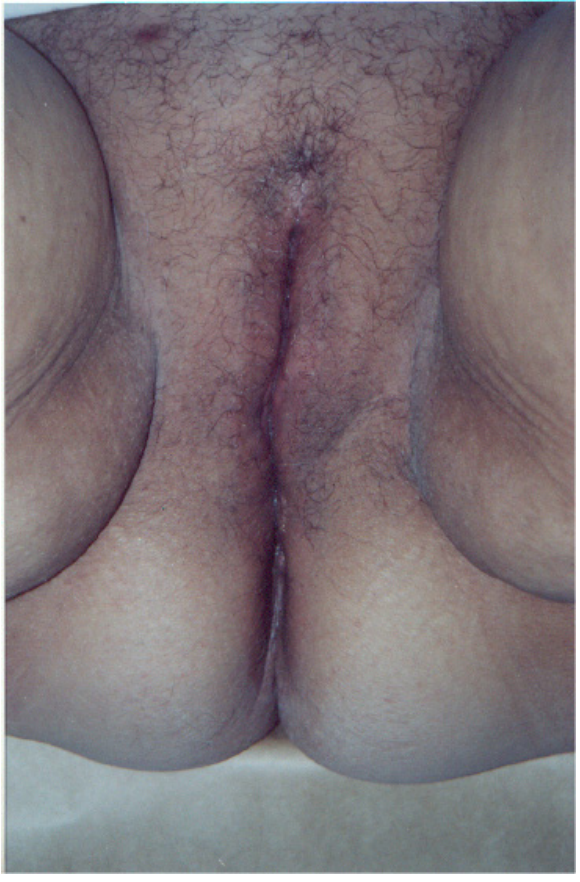

Figura 7 - Pós-operatório no $45^{\mathrm{a}} \mathrm{dia}$.

\section{Discussão}

Atualmente, aceitam-se duas origens diferentes para as NIVs. Uma ocorre em pacientes mais jovens, com fatores de risco semelhantes àqueles associados com a neoplasia intra-epitelial cervical (HPV, tabagismo e múltiplos parceiros sexuais). A outra ocorre em pacientes mais velhas, com historia de prurido vulvar por muitos anos ou associados ${ }^{1}$.

A história natural e a associação da NIV e do câncer do trato genital inferior com HPV têm sido estudadas. Demonstrou-se ser a presença de HPV fator necessário, mas não suficiente ${ }^{1,2,11}$. O DNA do HPV foi encontrado em 53 a 90\% das NIVs clássicas e o tipo mais freqüente foi o HPV $16^{13}$. Para o desencadeamento dos processos oncogênicos a presença de co-fatores se impõe. Verificou-se interação importante entre o tabagismo e história de longa data de verrugas genitais ${ }^{2,4}$. Não está ainda claro se as doenças como diabete melito, obesidade e hipertensão arterial representam fatores de risco independentes para o câncer de vulva ou meramente coexistem devido à idade ${ }^{4}$.

No presente caso, a paciente apresentava líquen simples crônico associado com líquen escleroso (diagnóstico clínico), NIV III com aspecto basalóide e HPV. Apesar de a carga viral estar muito baixa no exame de captura híbrida, o resultado histopatológico mostrou a presença do efeito citopático viral. O HPV e o líquen escleroso são dois 
fatores de risco para o desenvolvimento do câncer de vulva, assim como o tabagismo e a doença multifocal. Cerca de $80 \%$ dos cânceres de vulva em pacientes mais velhas estão associados ao líquen escleroso e/ou líquen simples crônico e/ou a hiperplasia de células escamosas não tratados ${ }^{3}$.

A presença do DNA do HPV foi constatada em $21 \%$ dos casos de cânceres escamosos invasivos bem diferenciados, em 75\% das lesões invasivas com morfologia basalóide e em 100\% das lesões invasivas verrucosas ${ }^{10}$.

Carlson et al. ${ }^{14}$ analisaram sessenta casos de carcinoma escamoso de vulva, enfatizando as alterações da pele adjacente à neoplasia, e constataram a presença de liquen simples crônico em $82 \%$ dos casos, de líquen escleroso em 65\%, de líquen simples crônico e líquen escleroso em $77 \%$ e de NIV III no campo do líquen escleroso em 43\% dos casos estudados.

Sykes et al. ${ }^{15}$, ao correlacionarem o achado da colposcopia vulvar com o resultado histopatológico, notaram concordância em $72 \%$ das pacientes pesquisadas e as margens cirúrgicas comprometidas em 66\%.

A estratégia para o manuseio da NIV III requer entendimento do potencial neoplásico da condição. O tratamento deve ser individualizado e conservador quando possivel, com o objetivo de aliviar os sintomas, de prevenir o câncer e de evitar mutilação vulvar ${ }^{16}$.

O comportamento da NIV clássica (verrucoso e basalóide) é altamente variável, pois cerca de 7 a $32 \%$ das pacientes apresentam recidiva ou persistência da doença e em 6 a $7 \%$ das vezes são identificadas áreas ocultas de invasão ${ }^{6}$. Para Jones ${ }^{16}$, as recorrências ocorrem em mais de $30 \%$ dos casos e estão relacionadas ao tabagismo, à distribuição multifocal das lesões e às margens cirúrgicas comprometidas pela doença. Outro estudo refere que $30 \%$ das pacientes com doença multifocal e tabagistas têm recorrências independente do tipo e da extensão do tratamento, incluindo a vulvectomia simples. Portanto, o aspecto mais importante do tratamento é o seguimento ${ }^{3,16}$.

Na presença de NIV III na região perineal é importante analisar a possibilidade de comprometimento da região perianal e do canal anal ${ }^{16}$. $\mathrm{O}$ melhor método para o rastreio é a anuscopia ${ }^{17}$. No caso em estudo a anuscopia estava normal e captura híbrida para HPV do canal anal, negativa.

A neoplasia intra-epitelial perianal e anal grau III é lesão precursora do carcinoma escamoso do ânus. Pode estar associada com NIC e/ou NIV e tem como agente causal o HPV ${ }^{17}$. Não há dados na literatura relatando uma estratégia terapêutica ótima ${ }^{17}$. Segundo Cleary et al. ${ }^{18}$, existe a necessidade de estudo comparando excisão local ampla com procedimento ablativo para se definir o tratamento da neoplasia intra-epitelial perianal.

A recidiva da neoplasia intra-epitelial perianal grau III ocorreu em 53,3\% dos pacientes tratados com excisão local, em $80 \%$ dos tratados com vaporização a laser e em apenas $23,1 \%$ dos casos quando foi realizada excisão local ampla ${ }^{19}$.

A vulvectomia superficial tem alta taxa de sucesso no tratamento de NIV III, com baixo indice de complicações e com resultado estético e funcional satisfatórios ${ }^{10,11}$. As lesões perianais também podem ser excisadas cirurgicamente. Geralmente esta abordagem ocasiona dor e desconforto por cerca de três semanas ${ }^{12}$.

A ablação a laser está associada a taxas mais altas de recorrência e não se encontra disponivel na maioria dos serviços ${ }^{12}$. A desvantagem do tratamento destrutivo é que são necessários cerca de três meses para cicatrização completa, que pode ocasionar dor por período de tempo mais longo. $\mathrm{O}$ preferivel mesmo é a excisão cirúrgica local, evitando procedimentos radicais, sendo que o tecido excisado pode revelar lesão microinvasora ${ }^{11}$. Segundo Sykes et al. ${ }^{15}$, não é aconselhável cirurgia radical para a NIV. Embora não exista tratamento padrão definido, os trabalhos apontam para a cirurgia, respeitando a margem de segurança, como o mais adequado ${ }^{2,7,16}$.

Ayhan et al. ${ }^{20}$ pesquisaram 21 pacientes com NIV II e III, as quais foram submetidas a vulvectomia superficial. As margens cirúrgicas estavam comprometidas pela lesão em apenas um caso e as complicações cirúrgicas foram febrícula e deiscência em três pacientes. Esse mesmo estudo refere as vantagens da realização desse procedimento, pois fornece material para a avaliação histopatológica e permite resultado estético e funcional satisfatórios.

Concluímos enfatizando a importância do exame da vulva, do conhecimento da história natural da NIV, do tratamento individualizado e do seguimento, considerando a alta porcentagem de recidiva.

\section{ABSTRACT}

High-grade vulvar intraepithelial neoplasia (VIN III) is a visible lesion; therefore, it is accessible to biopsy and thus, to a histological diagnosis. There are two forms of vulvar cancer precursors: VIN caused by human papillomavirus (HPV) and VIN associated with untreated lichen simplex chronicus, squamous cell hyperplasia, and lichen sclerosus. There may be overlap of the two forms. The term bowenoid papulosis, although discouraged, identifics a clinical form of VIN III. Such lesion appears as pigmented, wart-like growths or papules. VIN III is associated with HPV in more 
than $80 \%$ of the cases, and there is perianal involvement in $40 \%$ of the times. Vulvar intraepithelial neoplasia is difficult to cure and relapses can occur at any time for many years. Although there is no defined standard treatment, studies point to surgery, respecting a free margin, as the most adequate one.

KEYWORDS: Vulvar intraepithelial neoplasia (VIN). Perianal intraepithelial neoplasia. Skinning vulvectomy.

\section{Referências}

1. Creighton L, et al. Neoplasia intra-epitelial vulvar e câncer de vulva. In: Mitchell MF, Schottenfeld D, Hong WK, editors. Clínicas Obstétricas e Ginecológicas da América do Norte: prevenção do câncer ginecológico. Rio de Janeiro: Interlivros; 1996. p.289-305.

2. Ferenczy A. Vulval intraephitelial neoplasia. In: Apgar SB, Brotzman GL, Spitzer M, editors. Colposcopy: principles and practice. An integrated textbook and atlas. $1^{\text {st }}$ ed. Philadelphia: Saunders; 2002. p.359-63.

3. Davis G. Vulval intraephitelial neoplasia: clinical manifestations. In: Apgar SB, Brotzman GL, Spitzer M, editors. Colposcopy: principles and practice. An integrated textbook and atlas. $1^{\text {st }}$ ed. Philadelphia: Saunders; 2002. p.365-71.

4. Burke TW, Eifel PJ, Mcguire PW, Wilkinson JE. Vulva. In: Hoskins WJ, Perez CA, Young RC, editors. Principles Practice of Gynecology Oncology. $3^{\text {rd }}$ ed. Philadelphia: Lippincott Williams \& Wilkins; 2000. p.777.

5. Margesson L. Non-neoplastic epithelial lesions of the vulva. In: Apgar SB, Brotzman GL, Spitzer M, editors. Colposcopy: principles and practice. An integrated textbook and atlas. $1^{\text {st }}$ ed. Philadelphia: Saunders; 2002. p.346-55.

6. Hart WR. Vulvar intraepithelial neoplasia: historical aspects and current status. Int J Gynecol Pathol 2001; 20:16-30.

7. Pala S, Poleva I, Totino F, Antonelli G. Bowenoid papulosis: myth or reality? Minerva Gynecol 2000; 52 (Suppl 1):68-74.

8. Basta A, Adamek K, Pitynski K. Intraepithelial neoplasia and early stage vulvar cancer. Epidemiological, clinical and virological observations. Eur J Gynaecol Oncol 1999; 20:111-4.
9. Jones RW, Rowan DM. Spontaneous regression of vulvar intraepithelial neoplasia 2-3. Obstet Gynecol 2000; 96:470-2.

10.Singer A, Monaghan JM. Colposcopia: Patologia e tratamento do trato genital inferior. $2^{a}$ ed. Rio de Janeiro: Revinter; 2002. p.251-323.

11.Disaia PPJ, Creasman WTT. Clinical gynecology. $6^{\text {th }}$ ed. St Louis: Mosby; 2002. p.40-51.

12. Barrasso R, Gross GE. Infecção por papilomavirus humano. Atlas clínico de HPV. $1^{\text {a }}$ ed. Porto Alegre: Artmed; 1999. p.373.

13.Yang B, Hart WR. Vulvar intraepithelial neoplasia of the simplex (differentiated) type: a clinicopathologic study including analysis of HPV and p53 expression. Am J Surg Pathol 2000; 24:426-41.

14.Carlson AJ, Ambros R, Malfetano J, et al. Vulvar lichen sclerosus and squamous cell carcinoma: a cohort, case control, and investigational study with historical perspective; implications for chronic inflammation and sclerosis in the development of neoplasia. Hum Pathol 1998; 29:932-48.

15.Sykes P, Smith N, McCormick P, Frizelle FA. Highgrade vulval intraepithelial neoplasia (VIN 3): a retrospective analysis of patient characteristics, management, outcome and relationship to squamous cell carcinoma of vulva 1989-1999. Aust N Z J Obstet Gynaecol 2002; 42:69-74.

16.Jones RW. Vulval intraepithelial neoplasia: current perspectivas. Eur J Gynaecol Oncol 2001; 22:393402.

17.Browse DJ. Baigrie RJ, Goldeberg PA, Nevin JF. Radical excision of multifocal anal intraepithelial neoplasia: report of a case. Dis Colon Rectum 2001; 43:548-50.

18.Cleary RK, Schaldenbrand JD, Fowler JJ, Schuler JM, Lampman RM. Perianal Bowen's disease and anal intraepithelial neoplasia: review of the literature. Dis Colon Rectum 1999; 42:945-51.

19. Marchesa P, Fazio VW, Oliart S, Goldblum JR, Lavery IC. Perianal Bowen's disease: a clinicopathologic study of 47 patients. Dis Colon Rectum 1997; 40:1286-93.

20.Ayhan A, Tuncer ZS, Dogan L, Yuce K, Kucukali T. Skinning vulvectomy for the treatment of vulvar intraepithelial neoplasia 2-3: a study of 21 cases. Eur J Gynaecol Oncol 1998; 19:508-10. 


\section{Laboratório: Estalis / Estradot Anúncio: Novartis}




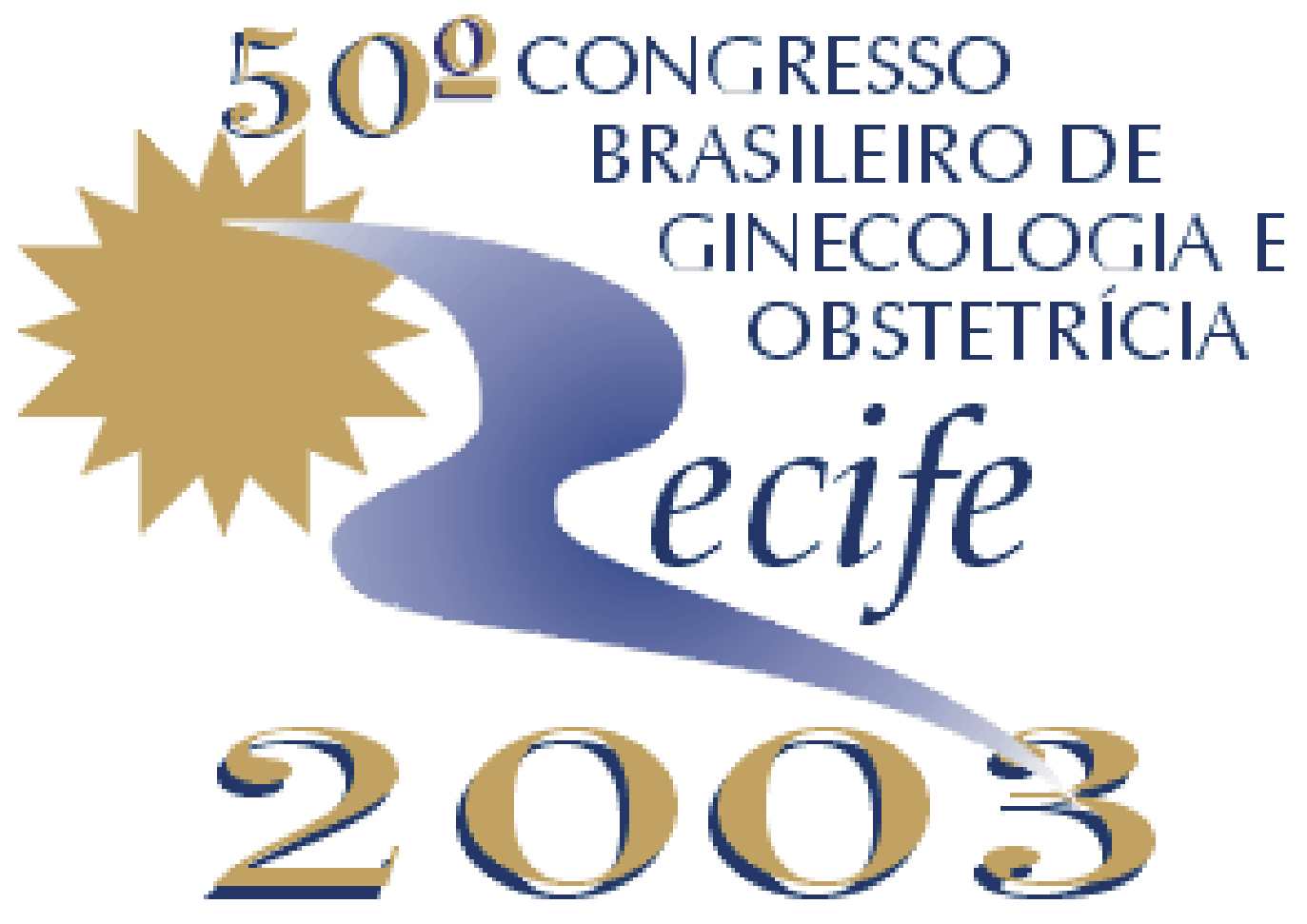

18 a 22 de novembro

\section{INFORMAÇŌES:}

Telefone: (81) 3222-5112

E-mail: sogope1@terra.com.br 